\title{
Metal(loid) Diagenesis in Mine-impacted Sediments of Lake Coeur d'Alene, Idaho
}

AUTHOR NAMES Gordon R. Toevs, ${ }^{\dagger}$ Matthew J. Morra, ${ }^{* \dagger}$ Matthew L. Polizzotto, ${ }^{\ddagger}$ Daniel G. Strawn, ${ }^{\dagger}$ Benjamin C. Bostick, ${ }^{\ddagger}, \S$ and Scott Fendorf ${ }^{*}$

Number of pages in Supporting Information Section: 6, including cover

Number of figures in Supporting Information Section: 7 

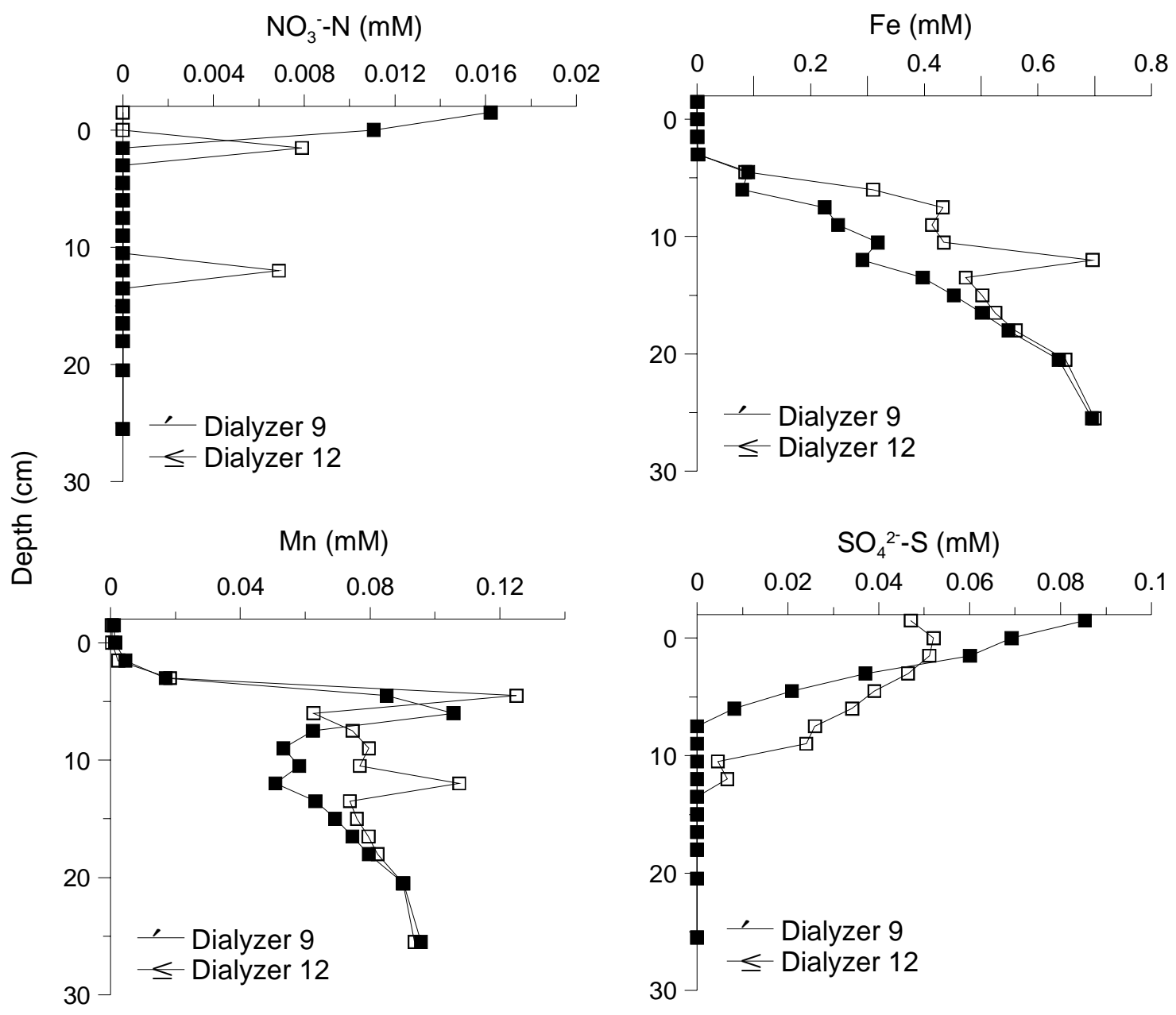

Supporting Information, Figure S1. Replicates of redox sensitive species from the Harlow Point site, May 2002 deployment, indicating the consistency of the trends and reproducibility of dialyzer samples. These trends are consistent with those found during five deployments from 2000 to 2002. Depth increments less than zero (0) indicate concentration above the sediment-water interface. 


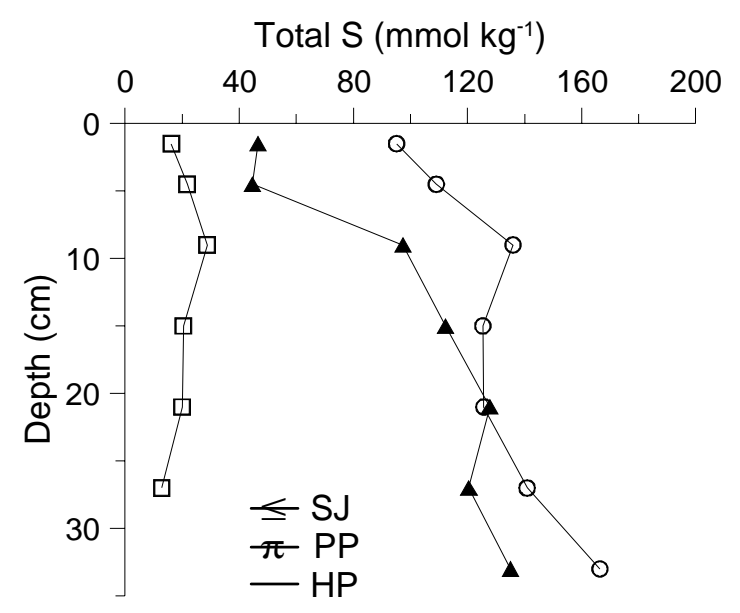

Supporting Information, Figure S2. Total S concentration of Lake Coeur d'Alene sediments in the control site (SJ) and the two contaminated sites (PP and HP). Total S determined by ICP analysis of sediment microwave digestions. Each point is an average of two samples from adjacent cores collected May 2002.

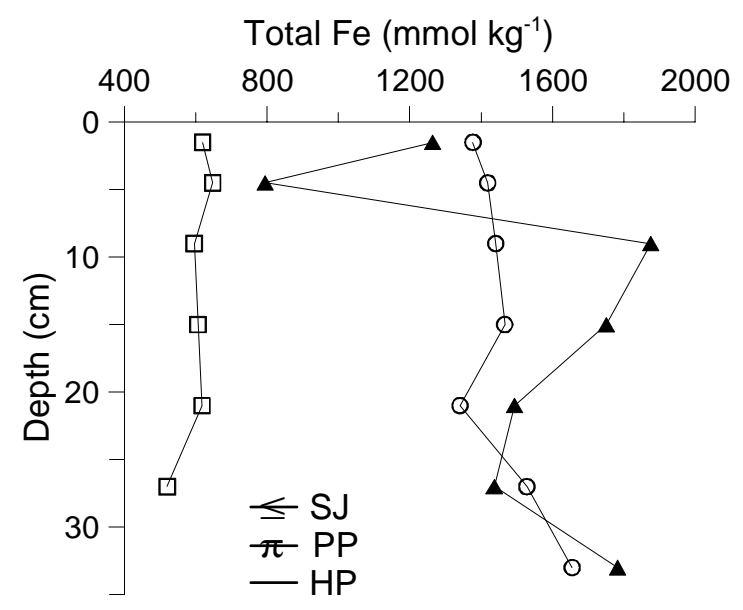

Supporting Information, Figure S3. Total Fe concentrations of Lake Coeur d'Alene sediments in the control site (SJ) and the two contaminated sites (PP and HP). Total Fe determined by ICP analysis of sediment microwave digests. Each point is an average of two samples from adjacent cores collected May 2002. 


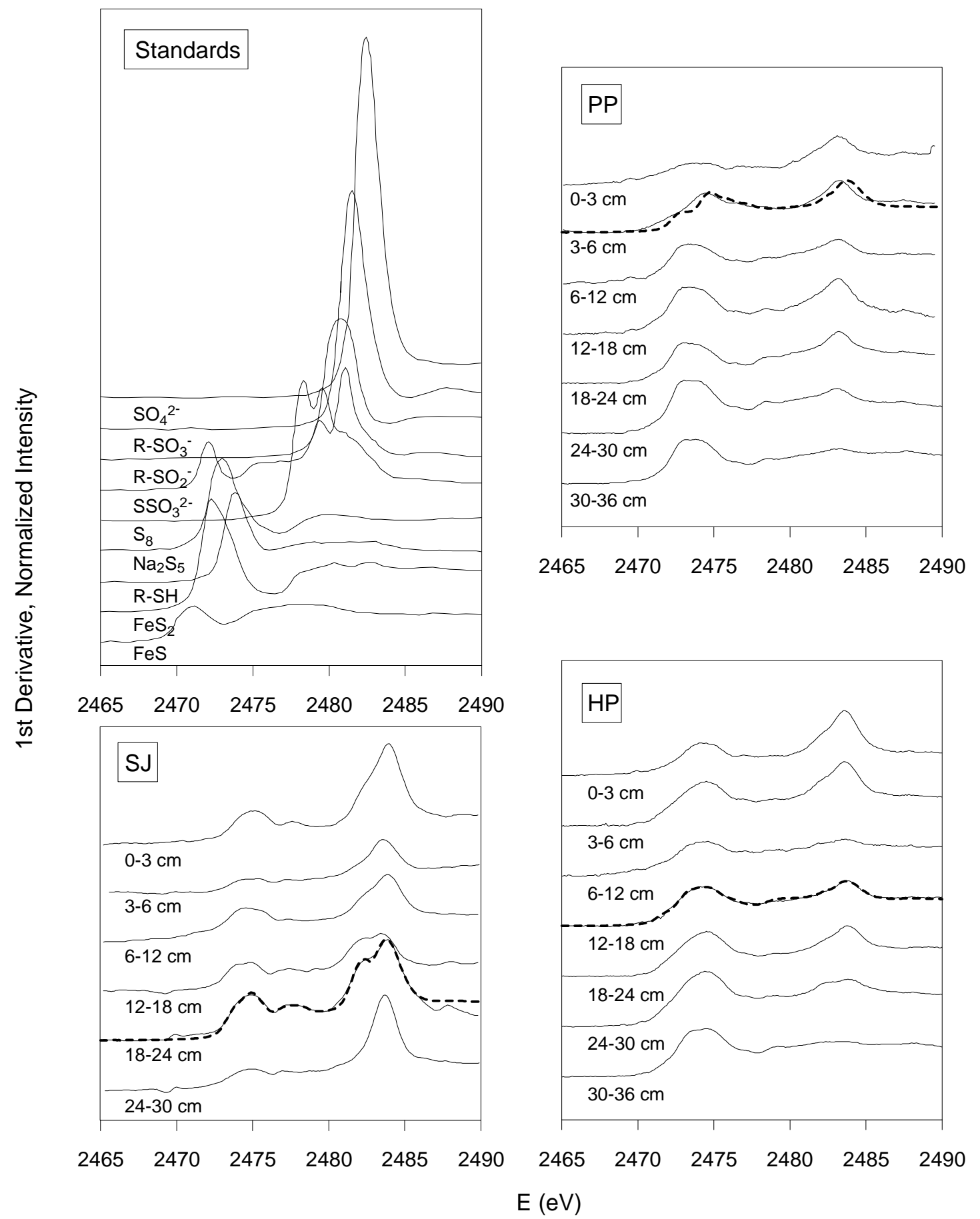

Supporting Information, Figure S4. S XANES standards and spectra of Lake CDA sediments from the control site SJ and the two contaminated sites PP and HP. Data are from cores collected May 2002 and analyzed at the Brookhaven advanced light source. The dashed lines are representative fitting curves. 

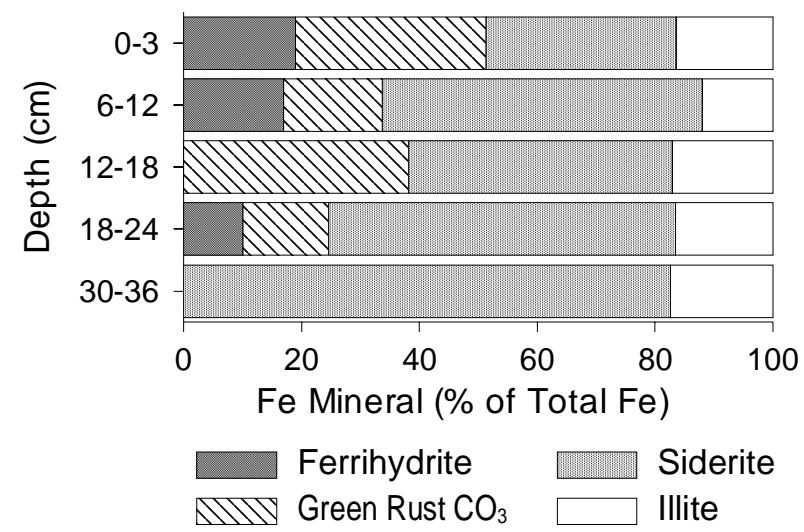

Supporting Information, Figure S5. Iron-EXAFS linear combination fitting for spectra from Harlow Point (HP) indicating the increase in siderite with depth. Minerals other than siderite and illite have not been verified by an additional independent technique. Data are from a core collected May 2002.

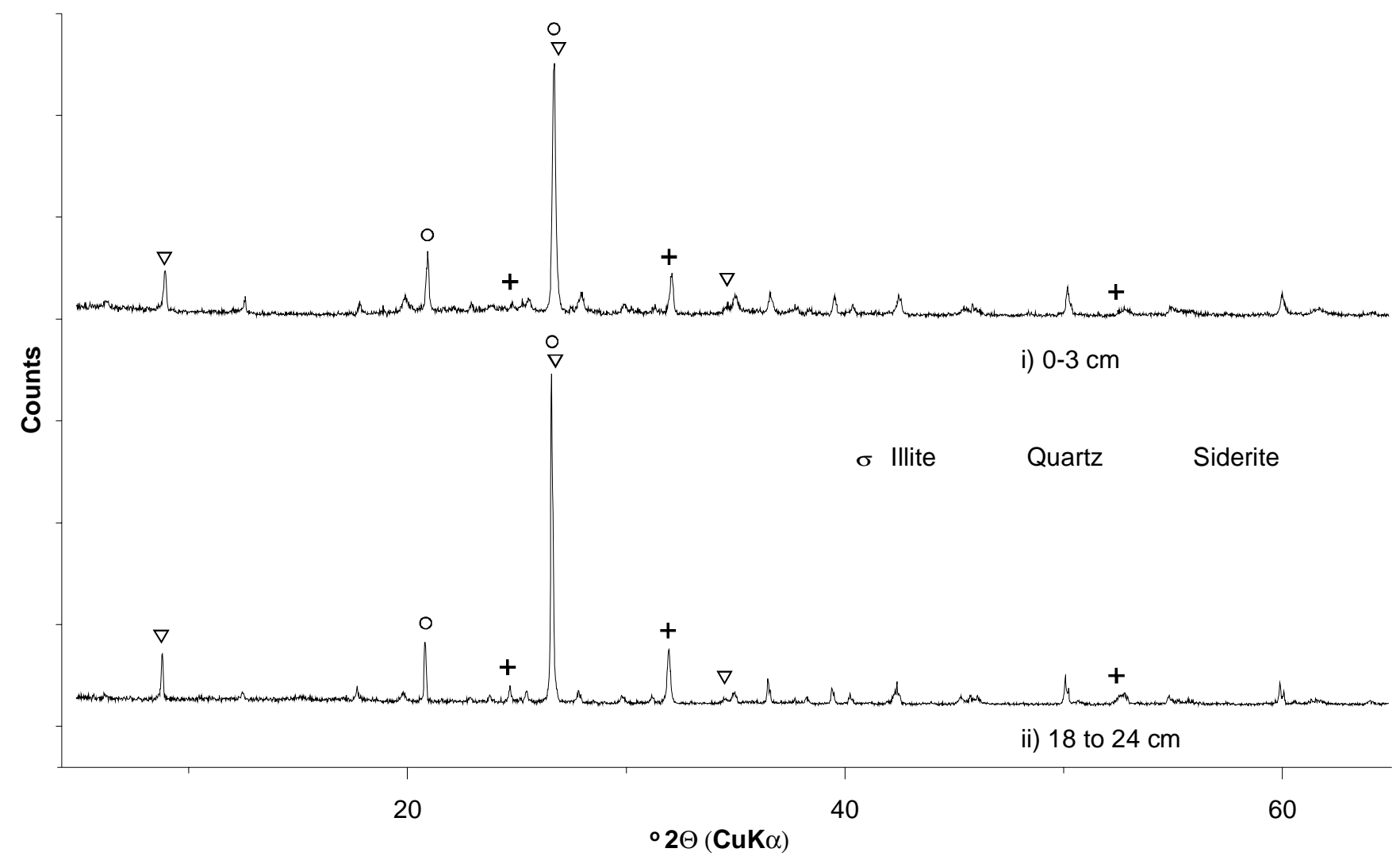

Supporting Information, Figure S6. XRD patterns identifying the presence of various minerals at Peaceful Point, Lake Coeur d'Alene. Data are from a core collected May 2002. 

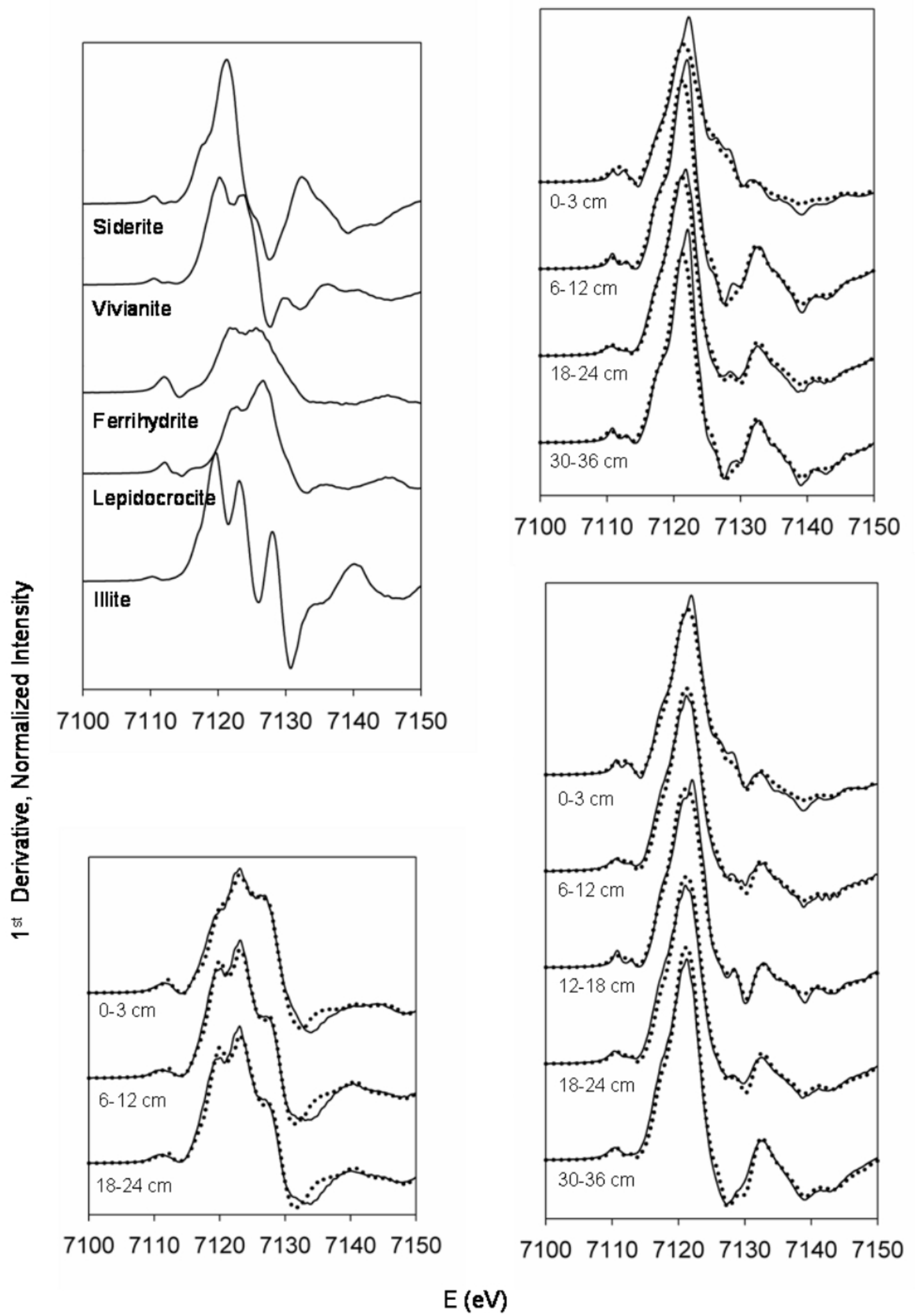

Supporting Information, Figure S7. Fe XANES standards and spectra of Lake CDA sediments. Data are from a core collected May 2002. 